\title{
VECTOR AUTOREGRESSIVE APPROACH AFTER FIRST DIFFERENCING: A TIME SERIES ANALYSIS OF INFLATION AND ITS DETERMINANTS IN TANZANIA
}

\author{
Rachel R. Cheti ${ }^{1}$, Bahati llembo ${ }^{2 *}$ \\ ${ }^{1}$ A student in Bachelor of Science in Applied Statistics, Mzumbe University, Tanzania \\ ${ }^{2}$ Department of Mathematics and Statistics Studies, Mzumbe University, Tanzania \\ rachelcheti87@gmail.com \\ bmilembo@mzumbe.ac.tz
}

\begin{abstract}
The objective of the study was to examine the trend of inflation and its key determinants in Tanzania. We used secondary time series data observed annually from January 1970 to 2020 which are inflation rate, GDP, Exchange rate and money supply. The vector autoregressive (VAR) model was employed for modeling. Augmented Dickey-Fuller test (ADF) found that inflation rate, Gross Domestic Product (GDP), exchange rate and Money supply (M3) were initially non-stationary but they became stationary after first differencing so as to proceed with the analysis. Preliminary tests before obtaining vector auto regressive model were carried out before determining the relationship between the variables. Diagnostic test such as serial correlation, heteroscedasticity, stability and normality were also important to evaluate the model assumptions and investigate whether or not there are observations with a large, undue influence on the analysis. We used Granger causality test (GCT) to determine causal- effect relationship between the variables. The results show that, there is a long run relationship between the variables, also the results showed that exchange rate and money supply (M3) both have a positive impact on inflation rate while gross domestic product (GDP) revealed a negative impact on inflation rate. Finally, the forecast of inflation rate for 15 years ahead was performed. The study recommends that the government should pursue both contractionary monetary policy and fiscal policy in order to control inflation in the country.
\end{abstract}

Keywords: Autoregressive, money supply, inflation

JEL classification: C32, C53, E17

\section{Introduction}

Inflation is one of the most difficult to define and bound complex phenomena (Baciu, 2015). It is referred to as a process in which the price index is rising and money is losing its value. It is a persistent increase of the general price level of the economy. Inflation rate is directly relate to gross domestic product, money supply, exports, prices of imports, exchange rate, interest rate, fiscal policy, inter alia (Bashir et al., 2011). Volatile inflation can be caused by major fluctuations in the demand and/or supply in the economy. The unstable and unpredictable inflation rates not only makes the long term planning difficult but also

\footnotetext{
* Corresponding author: Bahati llembo

Cite as:

Cheti, R. R. and Ilembo, B., 2021. Vector Autoregressive Approach after First

Differencing: a Time Series Analysis of Inflation and its Determinants in Tanzania.

Oradea Journal of Business and Economics, 6(2), pp. 43 - 56.

http://doi.org/10.47535/19910jbe128
} 
discourages both the investments and savings (Baciu, 2015). There are two types of economic effects as a result of uncertainty of inflation. The first one is an effect that occurs to companies and consumers that must take economic decisions taking into account the future inflation forecasted. According to Devereaux (1989), the uncertainty of inflation in this case affects financial markets by raising interest rates in the long term, leads to uncertainty regarding other variables that are important in economic decisions and encourages companies to direct their resources in order to avoid certain risks related to inflation. The second effect is when the inflation rate differs significantly from its projection. An inflation that is better than expected leads to a transfer of wealth from the creditor to the debtor. The latter is favoured because repayment is done with money whose purchasing power is penalized by the inflation rate.

It is argued that inflation is not a desirable situation due to its effects in both economic and social aspects (Khan and Gill, 2010). The causing factors of high inflation remained inconclusive by both monetary and fiscal perceptions. Inflation impacts on income distribution making a random redistribution of real income. Inflation that raises the price level in a country creates financial problems in raising the prices of commodities, services, and other factors. It is, therefore, found that inflation is one of the major reasons of raising the price level of different commodities in any economy. Inflation in Tanzania has been harmful to economic growth but do not show the degree of responsiveness of GDP growth rate to changes in the general price levels (Shitundu and Luvanda, 2000)

Inflation and inflation volatility in Sub-Saharan Africa (SSA) have been gradually declining. However, in the years 1980s, the region experienced high inflation rate which was also associated with fixed exchange rates and overvalued real exchange rates. This increase was due to subordinating monetary policy to the objective of financing fiscal deficits in the region (Berg et al., 2015). From the mid-1980s to the late 1990s countries began reform programs, often with exchange rate unifications and movement toward more marketdetermined exchange rates, notable reductions in central bank financing of government and financial liberalizations. The other main cause of inflation in SSA would be unpredicted rise in food costs.

Experience from Tanzania shows that, inflation was once recorded at an average of 8 per cent for consecutive 9 years, a high and risky inflation in the country (BoT, 2011). According to the Bank of Tanzania (BoT) report, this appeared to be a challenge in the macro economy. Various initiatives have been in place such as the macroeconomic reforms applied in the mid-1990s. These included such initiatives like booming up of the strong domestic output together with favorable global financial prerequisites which altogether helped keep headline inflation close to the authorities' indicative target of 5 percentages per annum. Data from the BoT reports shows that, in mid-2008, the country recorded a year-on-year headline inflation edged above 10 percent per annum for the first time given that of the early 1990s, and whilst it dropped back to low single digits in 2009, it rose again sharply in the direction of the give up of 2010, reaching close to 20 percentages per annum in the closing quarter of 2011(BoT, 2011).

According to BOT (Monetary Policy statement 2020-2021), headline inflation has shown a declining trend. The twelve-month headline inflation averaged 3.6 percent during July 2019 to April 2020, compared with 3.2 percent in the corresponding period of $2018 / 19$. There could be several reasons or explanations for this trend but mostly might be on account of adequate domestic food supply, prudent monetary and fiscal policies, stability of power supply, and significant decline in oil prices in the world market. Likewise, core inflation was low, averaging at 2.4 percent compared with 2.7 percent for the same periods. Further, inflation is projected to remain around the medium term target of 5.0 percent, in the range of 3.0 percent to 5.0 percent in $2020 / 21$, supported by adequate domestic food supply, low world oil prices, subdued demand, stable power supply and again, prudent monetary and fiscal policies. On the other hand, there are real factors such as food production, which also 
influences inflation (BoT, 2020)

The purpose of this study is to examine the trend of inflation and its key determinants in Tanzania using VAR. The model incorporated both the demand and cost-push or structural elements of price movements. It is based on annually data which simultaneously explores the importance of time lags of key variables that includes money supply, exchange rate and GDP.

\section{Methodology}

The study used the strengths of documentary review and secondary data, which were compiled annually for the period of 51 years from 1970 to 2020 by the Bank of Tanzania and the Ministry of Finance and Planning. Such data include Inflation rates, Money supply, Exchange rate and Gross Domestic Products. According to McCleary et al (1980), time series analysis suffices to use not less than twenty (20) observations. However, to obtain robust results, it is recommended to fit time series models with at least 50 observations. More data is always preferable, but at the very least, a time series should be long enough to capture the phenomena of interest. Henceforth, the study uses a sample of 51 years for the data taken on yearly basis from 1970 to 2020 . This is healthy number of observations in any data to take the result on VAR model. We used STATA 14 to analyze the time series data.

\subsection{Technical considerations and model specification}

\subsubsection{Testing for Stationarity (Unit Root Test)}

In testing for stationarity of a time series, one must ensure that statistical properties such as average, standard deviation and autocorrelation do not change over time, that is they are constant. Non- stationary data have got the disadvantage of producing spurious results or non-sense results (Gujarati, 2004). Augmented Dickey Fuller Test (ADF) was used to test the unit root problem. The ADF was preferred because it includes extra lagged terms of the dependent variables in order to eliminate autocorrelation in the test equation when the error term is unlikely to be white noise. The ADF used to estimate the following equation;

$$
\Delta \mathrm{Y}_{\mathrm{t}}=\beta+\delta \mathrm{Y}_{\mathrm{t}-1}+\sum_{\mathrm{t}=1}^{\mathrm{m}} \alpha_{\mathrm{i}} \Delta \mathrm{Y}_{\mathrm{t}-1}+\varepsilon_{\mathrm{i}}
$$

The null hypothesis for the test is that a variable is not stationary (has a unit root) against the alternative hypothesis that it is stationary (has no unit root). If the data is not stationary, we will transform them to stationary time series by differencing. The difference time series is the change between each observation in the original series over time.

$$
Y_{t}=Y_{t}-Y_{t-1}
$$

\subsubsection{Granger Causality Test}

The assessment of causal- effect relationship among variables is important in time series analysis and in this context, Granger causality test is used to test whether one time series is useful in forecasting another (Farook and Kannan, 2015). If a variable $Y$ can be predicted by another variable, say $X$ then the Granger test may reveal the causal- effect relationship between $Y$ and $X$. The test statistic to test the null hypothesis that $X$ does not granger-cause $Y$ and the alternative hypothesis that $X$ does Granger cause $Y$ is given by:,

$$
\mathrm{F}=\frac{\left(\mathrm{RSS}_{\mathrm{R}}-\mathrm{RSS}_{\mathrm{UR}}\right) / \mathrm{m}}{\mathrm{RSS}_{\mathrm{R}} /(\mathrm{n}-\mathrm{k})}
$$

Where;

$\mathrm{RSS}_{\mathrm{R}}=$ restricted residual sum of square 


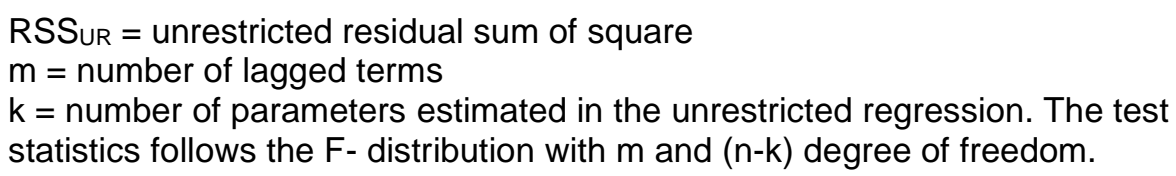

\subsubsection{Conceptual framework and definition of variable}

The conceptual framework involves dependent and independent variables which guides the assessment of the causal -effect relationships hypothesized to exist between the variables. The dependent variable is inflation rate(IR) and is measured in per centage and independent variables are namely money supply (M3), measured in billions TZS, exchange rate (ER), measured in US dollars and gross domestic product (GDP) in millions TZS as shown in figure 1.

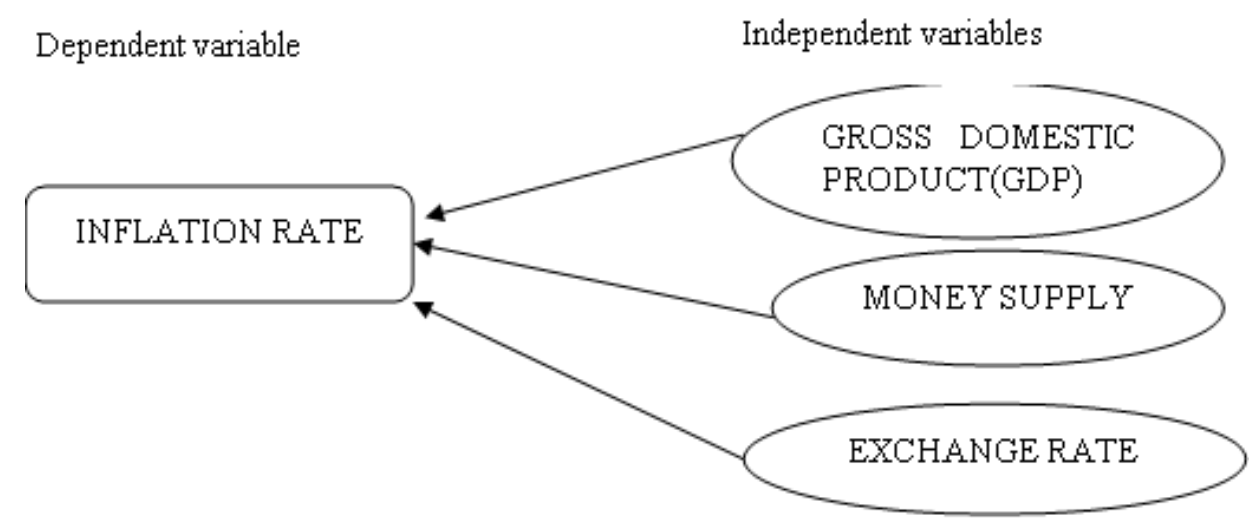

Figure 1: Conceptual framework of the variables in the model

Source: Researcher's own construct, 2021

\subsubsection{Model specification}

This paper has used Ordinary Least Squares by employing the Vector Autoregressive Model (VAR). This is the suitable estimation technique to be used because it has the ability to provided the existence of the short run relationship or past and causal relationship between the Inflation rate and its determinants such as Growth Domestic Products (GDP), exchange rate (ER) and the money supply (M3) in time (Mantua, 2004). Therefore, VAR commonly employs the multivariate regression time series analysis technique. The model used in this paper have the following functional form:

$$
I R_{t}=\beta_{0}+\beta_{1} \ln G D P_{t}+\beta_{2} \ln M 3_{t}+\beta_{3} \ln E R_{t}+\varepsilon_{t} \ldots \ldots \ldots \ldots \ldots \ldots \ldots \ldots \ldots \ldots \ldots \ldots \ldots \ldots \ldots \ldots \ldots
$$

Where, IR denotes an inflation rate (Dependent variable), InGDP denotes the natural log of growth domestic products (GDP), InM1 denotes the natural log of money supply and ER denotes the Exchange rate, $\beta_{0}$ is a constant term, $\beta_{1}-\beta_{3}$ are parameters estimates, and $\varepsilon_{t}$ denotes a stochastic term. It can be seen from the model that the dependent variable is not logarithmic while independent variables are logarithmic. There are three reasons to transform a variable by taking the natural logarithm. These reasons will determine whether one wants to log the explanatory variable (s), response variable or both. The idea is to improve model fit. In our case, we found independent variables (Exchange rate, GDP and Money supply) were not normally distributed and with huge values compared to the response variable (Inflation rate). Taking logarithm of a skewed variable may improve the fit by altering the scale and making the variable more normally distributed. 


\section{Results and discussion}

\subsection{Descriptive statistics results}

Table 1 gives a summary of descriptive statistics of the explanatory variables and the response variable.

Table 1: Summarized descriptive statistics

\begin{tabular}{|l|r|c|c|r|r|}
\hline \multicolumn{1}{|c|}{ Variable } & Obs & Mean & Std. Dev. & Min & Max \\
\hline INF_RATE & 51 & 15.60784 & 11.09994 & 2.4 & 36.1 \\
\hline LnER & 51 & 5.215904 & 2.278747 & 1.931521 & 7.746344 \\
\hline LnGDP & 51 & 14.27969 & 3.182715 & 9.12402 & 18.69232 \\
\hline InM3 & 51 & 6.027422 & 3.079219 & .7929925 & 10.26702 \\
\hline
\end{tabular}

Source: Fieldwork data, 2021

It is revealed from Table 1 that, the minimum value of inflation rate is 2.4 percent and a maximum value is 36.1 percent. The mean inflation rate value is 15.61 while the standard deviation obtained is 11.1. The GDP ranged from 9.12 (to 2 decimal places) to a maximum value of 18.69 (to 2 decimal places). The GDP have got a mean value of 14.27969 and a standard deviation of 3.182715. Similarly, money supply (M3) ranged from a minimum value of 0.79 to a maximum value of 10.267 with an average of 6.0274 and a standard deviation of 3.0792. Finally, the Exchange rate ranged from a minimum of 1.93 to a maximum of 7.746 with the mean value of 15.609 and a standard deviation of 2.2787.

\subsection{Trends of inflation in Tanzania}

Figure 2 presents how Tanzania experienced inflation for 51 years since 1970 to 2020. It is vivid that inflation was continually rising to the mid of 1970's where it felled down and rose up again. In the period of 1980's namely (1980-1990) Tanzania witnessed very high rate of inflation to a peak of $36.1 \%$ in 1984 and $35.9 \%$ in 1990. In 1991 inflation began to fall down but it rose again up to $35.3 \%$ in 1994. In the late 1990 s, inflation rate went down and according to Laryea and Sumaila (2001) this downward trend of inflation rate is a result of the impact of tight monetary and fiscal policies implemented by the central bank. The decline continued and reached up to $4.6 \%$ in 2002 and began to rise again 2008 and reached $16 \%$ in 2012 but again fall down in 2013 and reach $3.7 \%$ in 2020.

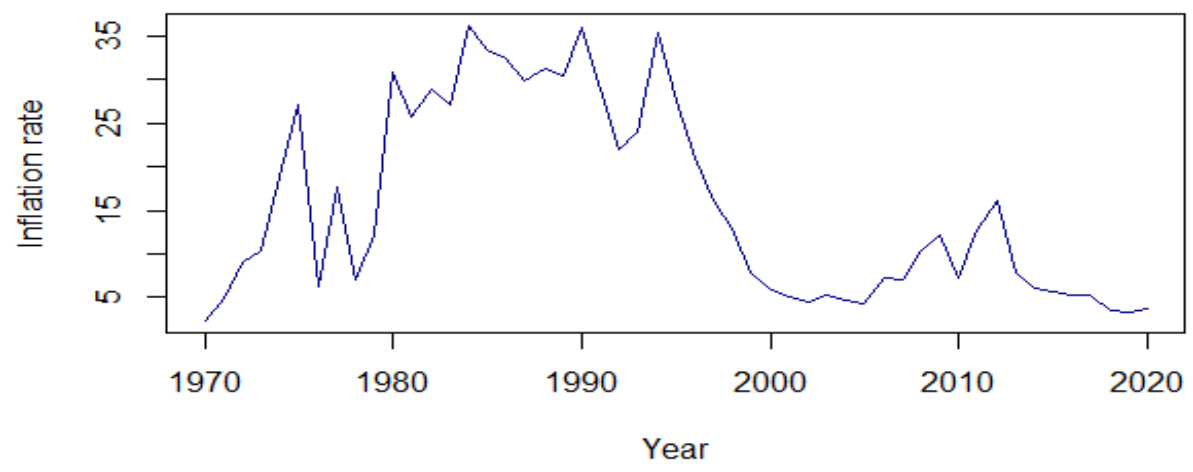

Figure 2: Trend line of Inflation Rate in Tanzania from 1970-2020

Source: Fieldwork data, 2021 
Through all this time the minimum inflation rate ever recorded was $2.4 \%$ in 1970 and the maximum inflation rate ever recorded was $36.1 \%$ in 1984 . The upward and downward movement of inflation trend may be due to impact of change in monetary and fiscal policy, the sharp rise of inflation in the late 1970's was due to many internal and external shocks not captured in this study.

In additional the study reveals that GDP, exchange rate and money supply have an upward trend.

\subsection{Analysis of the series stationarity}

Hypothesis for the unit root test;

HO: Variables are not stationary (variables have Unit root).

H1: Variables are stationary (variables have no unit root).

The null hypothesis is rejected if the calculated value of the test statistic is greater than the absolute value of the critical value. Otherwise, we do not reject the null hypothesis. Table 2 below presents the unit root test at $5 \%$ level of significance equivalent to $95 \%$ level of confidence.

Table 2: Unit Root at 95\% level of confidence

\begin{tabular}{|c|c|c|c|c|}
\hline \multirow[b]{2}{*}{ Variables } & \multicolumn{2}{|c|}{ At Level } & \multicolumn{2}{|c|}{ First $\quad$ Difference } \\
\hline & $\begin{array}{c}\text { Test } \\
\text { Statistics }\end{array}$ & $\begin{array}{c}c \text { Critical } \\
\text { Value at } 5 \%\end{array}$ & $\begin{array}{c}\text { Test } \\
\text { Statistics }\end{array}$ & $\begin{array}{c}\text { Critical } \\
\text { Value at } 5 \%\end{array}$ \\
\hline INF_RATE & -2.906 & -3.500 & -9.176 & -3.504 \\
\hline LnER & -0.571 & -3.500 & -4.830 & -3.504 \\
\hline LnGDP & -0.141 & -3.500 & -5.269 & -3.504 \\
\hline LnM3 & 1.005 & -3.500 & -4.376 & -3.504 \\
\hline
\end{tabular}

Source: Fieldwork data, 2021

The result in Table 2 shows that the data were not-stationary at level I (0). With respect to all variables the null hypothesis is accepted that the time series data is not stationary. After first differencing, all the data series became stationary or integrated at first order which implies that, the null hypothesis at first difference were rejected in favor of the alternative hypothesis for all data series and this is because Augmented Dickey Fuller (ADF) test for the probability values in all variables is less than $5 \%$ level of significance. 


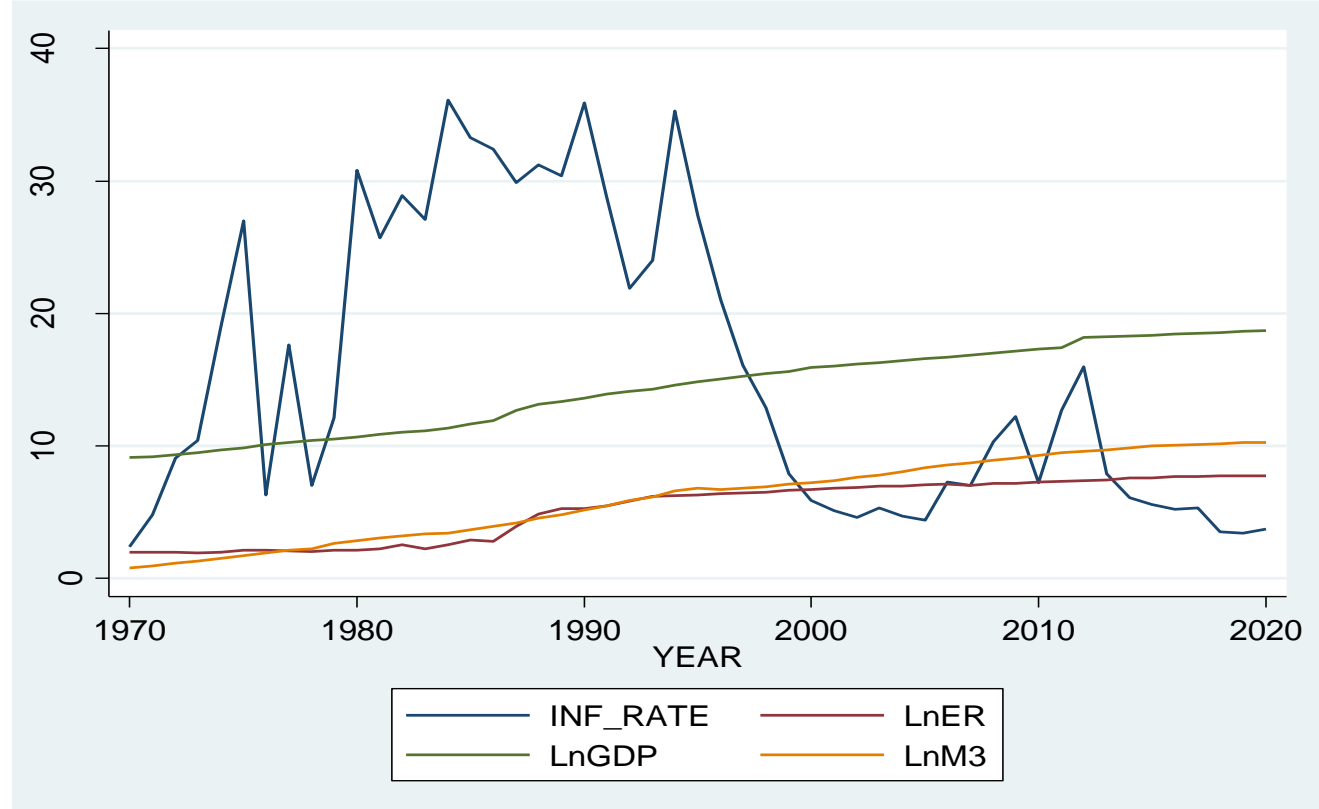

Figure 3: Line graph for non-stationary data Source: Fieldwork data, 2021

Figures 3 and 4 shows line graphs for non- stationary data and stationary data respectively. Line graph presented in figure 4 was obtained after first differencing. In the first place, data was not stationary. Obtaining stationary data was important in order to proceed fitting of the VAR model.

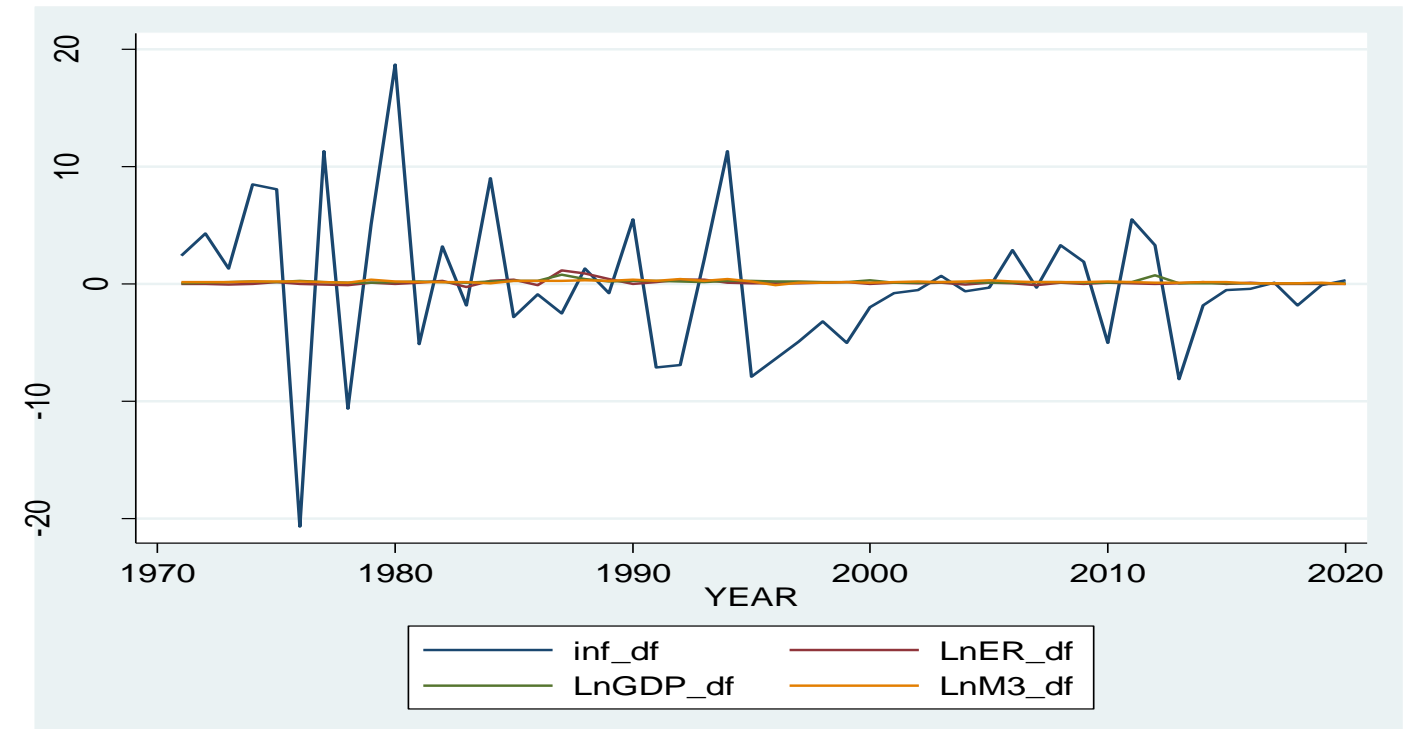

Figure 4: Line graph for stationarity data (after first differencing)

Source: Fieldwork data, 2021

\subsection{Lag Length Selection}


Before running the Vector autoregression, there must be established number of lags that will be used during VAR test. In this section we are going to estimate AR lag length $p$, which is not known (but can be estimated) by using various lag lenght selection criteria. The available selection criteria includes Akaike's information criteria (AIC), Schwarz information criteria (SIC), Hannan- Quinn criterion (HQC), Final Prediction error (FPE) and Bayesian information criteria (BIC). The autoregressive lag length of time series explains how the current value depends on its first $p$ lagged values which is normally denoted as $A R(p)$. Table 3 shows the estimated values.

Table 3: Selection of the Optimum Number of Lags

\begin{tabular}{|c|c|c|c|c|c|c|c|c|}
\hline Lag & LL & LR & Df & $p$ & FPE & AIC & HQIC & SBIC \\
\hline 0 & -307.032 & & & & 6.57923 & 13.2354 & 13.2947 & 13.3929 \\
\hline 1 & -44.7963 & 524.47 & 16 & 0.000 & $.000186^{*}$ & $2.75729^{*}$ & $3.05355^{*}$ & $3.54458^{*}$ \\
\hline 2 & -31.5815 & $26.43^{*}$ & 16 & 0.048 & .000213 & 2.87581 & 3.40908 & 4.29294 \\
\hline 3 & -22.3738 & 18.415 & 16 & 0.300 & .000295 & 3.16484 & 3.93513 & 5.21181 \\
\hline 4 & -10.0341 & 24.679 & 16 & 0.076 & .000373 & 3.3206 & 4.3279 & 5.99741 \\
\hline
\end{tabular}

Source: Fieldwork data, 2021

Table 3, presents the lag selection process from which lag 1 was selected to be the optimum lag worthy to be used in Autoregressive integrated moving average (ARIMA) modelling. This is due to the fact that most of the lag selection criteria namely the Schwarz' Bayesian Information Criterion (SBIC), Akaike's Information Criterion (AIC), and the Hannan -Quinn information criterion (HQC) suggest lag 1, therefore here we used Akaike's Information Criterion (AIC) to select the optima lag and hence the lag that will be used is lag 1.

\subsection{Vector Auto Regressive (VAR)}

Vector Auto regressive (VAR) is a forecasting algorithm that can be used when two or moretime series influence each other. That is, the relationship between the time series involved is bi-directional. The smaller the $p$-value, the stronger the evidence that one should reject the null hypothesis which shows statistically significant of the test. The test was carried out at $5 \%$ level of significance and the results revealed that the second lag of exchange rate $(E R)$ is significant $(p-$ value $=0.032<0.05)$ and has a positive impact on inflation rate. This means that the second lag of exchange rate and inflation rate are not independent and the positive coeffcient implies that as lag of exchange rate increases, inflation rate also increases and vice versa. On the other hand, the first lag of gross domestic product (GDP) is significant $(p$ - value $=0.044<0.05)$ and has a negative impact on inflation rate. This also means that, the first lag of GDP and inflation rate are not independent though are having a reverse relationship that when one increases, the other one decreases. The first lag of money supply $(M 3)$ is significant $(p$-value $=0.002<0.05)$ and has a positive impact on Inflation but the second lag of money supply remain inconclusive since the $p$-value and the level of significant are the same. The results are shown in Table 4. 
Table 4: Vector auto regressive results

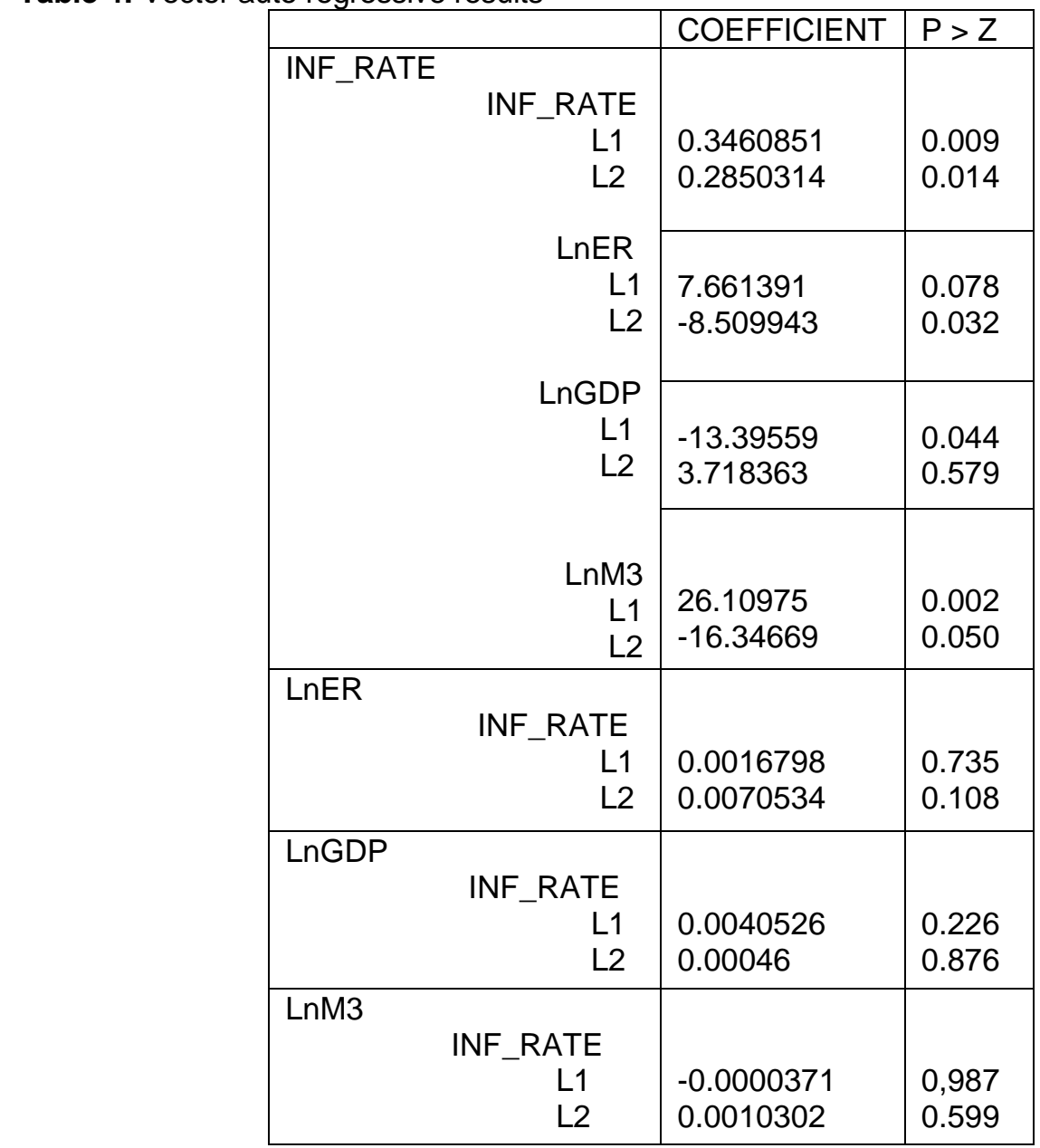

Source: Fieldwork data, 2021

Similar findings were also revealed by Khalid (2005) who examined determinants of inflation in Pakistan used a bivariate VAR and concluded that imported inflation, deficit-GDP ratio, exchange rate depreciation, were the important determinants of inflation. Numerous studies such as Nguyen, Cavoli and Wilson (2012) who analyzed the determinants of inflation in Vietnam using VAR model produced similar results as they revealed that money supply, external factors and output all play a role in the Vietnamese inflation process. Similarly, Khalid (2005) also concluded that imported inflation, deficit-GDP ratio, money depth, exchange rate depreciation, openness and domestic credit were the important determinants of inflation. Further, Abidemi and Maliq (2010) concluded that growth rate of GDP and Money supply give positive impression on inflation rate. While other explanatory variables such as fiscal deficit and exchange rate are indirectly associated to inflation.

A number of studies could not establish similar results on the determinants of inflation. A study by Alexander, Andow and Danpome (2015) could not establish gross domestic product as the cause of inflation until when it was analyzed together with import of goods and services, agricultural products and external factors. Similar results were also obtained in Nguyen, Cavoli and Wilson (2012). 


\subsection{Diagnostic Test}

The validity of the model used in this study was subjected to various diagnostics tests so as to justify whether the model was suitable for the study or not. The diagnostic test starts with the test for normality as presented in section 3.5.1

\subsubsection{Test for Normality}

It is customery to test for normality about residuals in order to validate the model that is used in the study. We used the Jarque - Bera test to check for normality and the results revealed that residuals are normally distributed (chi (2) value $=0.498$ which is greater than 0.05 ). Therefore, residuals are normally distributed. as shown in Table 5.

Table 5: Jarque-Bera test for normality

Jarque-Bera test for Ho: normality

$$
\begin{array}{|l|l|l|}
\hline \text { Jarque-Bera normality test: } & 1.394 & \text { Chi(2) } \\
\hline
\end{array}
$$

Source: Fieldwork data, 2021

\subsubsection{Autocorrelation Test}

Breuch-Godfrey Correction ML test was carried out to determine the existence of serial correction among residuals. The null hypothesis is that, there is no serial correlation within residuals against the alternative hypothesis that there is serial correlation within the residuals. However, the result showed that the observed $p$-value was found to be almost as equal as the level of significance with its value 0.0510 . Therefore, the null hypothesis can neither be rejected nor accepted since the results remains inconclusive. The test will show better results if the sample size would have been increased.

Table 6: Breusch-Godfrey LM test for autocorrelation

$\mathrm{HO}$ : no serial correlation

\begin{tabular}{|l|c|c|c|}
\hline lags $(\mathbf{p})$ & chi2 & Df & Prob > chi2 \\
\hline 1 & 3.808 & 1 & 0.0510 \\
\hline
\end{tabular}

Source: Fieldwork data, 2021

\subsubsection{Heteroscedasticity Test}

Breuch-Pagan test was carried out to test the residuals. The null hypothesis stated that the error variances are all equal (homoscedasticity), against the alternative hypothesis that the error variances are a multiplicative function of one or more variables (heteroscedasticity). The results revealed that the null hypothesis cannot be rejected since the observed $p$-value is 0.1832 which greater that the level of significance $(5 \%)$ and therefore the residuals were homoscedasticity. The results are shown in Table 7.

Table 7: Breusch-Pagan test for heteroscedasticity

Source: Fieldwork data, 2021

\begin{tabular}{|c|c|}
\hline \multicolumn{2}{|c|}{$\begin{array}{l}\text { Breusch-Pagan / Cook-Weisberg test for heteroscedasticity } \\
\text { Ho: Constant variance } \\
\text { Variables: myResiduals }\end{array}$} \\
\hline $\operatorname{chi} 2(1)$ & 1.77 \\
\hline Prob > chi2 & 0.1832 \\
\hline
\end{tabular}

\subsubsection{Stability test}

In order to test for the stability of the model at a given level of significance, Cumulative Sum (CUSUM) and Cumulative Sum Square (CUSUM of squares) are used and are called stability test. The null hypothesis tested in stability test is that, the model is stable against the alternative that the model is not stable. 


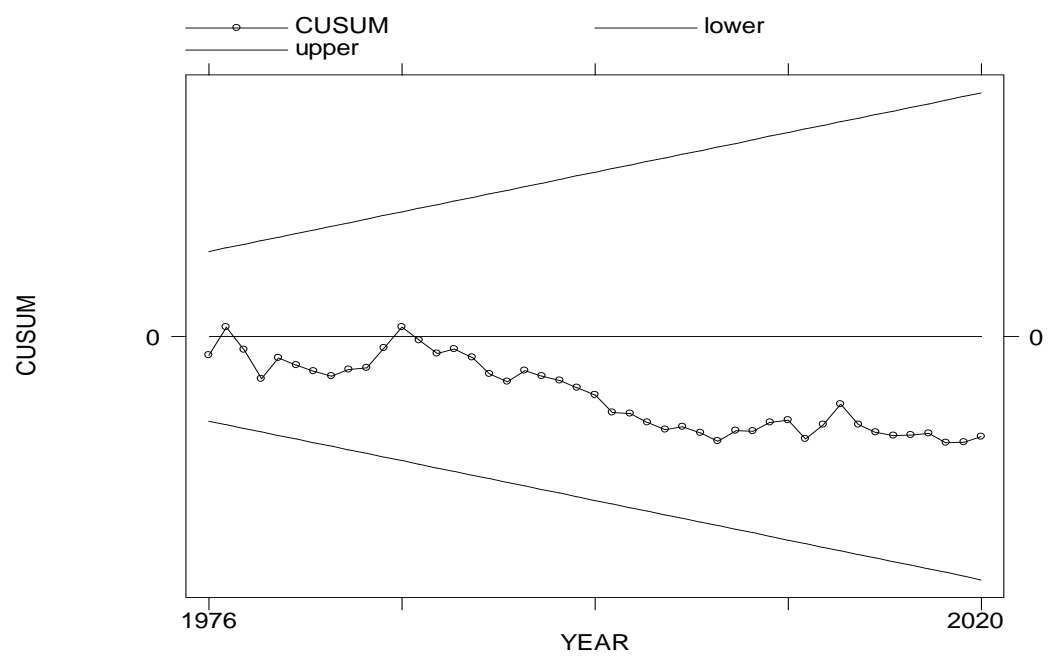

Figure 5: CUSUM results

Source: Fieldwork data, 2021

Results of Cumulative Sum (CUSUM) and Cumulative Sum Squares (CUSUM of squares) as evidenced in Figure 5 and Figure 6 show that the model was stable since the graphs of recursive residuals are within the boundary of the critical region. This is also in accordance with Xiao \& Phillips (2002), that a model is stable if the plot reveals that the CUSUM and CUSUM of squares of recursive residuals lie within the band of the critical values. Figure 6 represents a plot for CUSUM of squares and similar information is revealed.

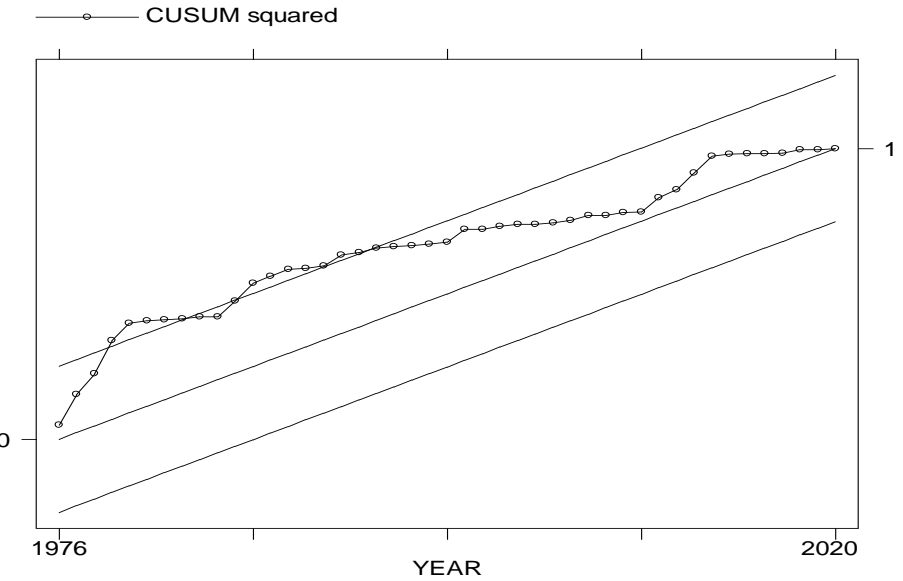

Figure 6: CUSUM square results

Source: Fieldwork data, 2021

\subsection{Granger causality Test}

In order to improve the forecast, granger causality test was performed and revealed that the money supply and GDP Granger cause inflation rate while exchange does not Granger cause inflation rate rather than inflation rate is the one that Granger cause exchange rate. In essence, the Granger causality test is used to examine causal-effect relationships between inflation rate and the selected explanatory variables, money supply, exchange rate and gross domestic product. The results of Granger causality Wald test shows that the 
observed $p$-value is greater that the level of significance $(0.05)$ that is 0.089 . This do not reject the null and therefore Exchange rate does not granger cause Inflation rate but in the other hand inflation rate is the one that granger cause exchange rate. On the other hand, since the observed $p$-value is less than 0.05 that is 0.03 , on the relationship between exchange rate and inflation rate, the null is rejected and we conclude that exchange rate granger cause inflation rate.

Table 8: Granger Causality Wald Test Results

\section{Granger causality Wald tests}

\begin{tabular}{|llccc|} 
Equation & Excluded & chi2 & df & Prob > chi2 \\
\hline INF_RATE & LnER & 4.8366 & 2 & 0.089 \\
INF_RATE & LnGDP & 6.1051 & 2 & 0.047 \\
INF_RATE & LnM3 & 12.734 & 2 & 0.002 \\
INF_RATE & ALL & 27.611 & 6 & 0.000 \\
\hline LnER & INF_RATE & 7.0084 & 2 & 0.030 \\
\hline LnGDP & INF_RATE & 3.5437 & 2 & 0.170 \\
\hline LnM3 & INF_RATE & .53338 & 2 & 0.766 \\
\hline
\end{tabular}

Source: Fieldwork data, 2021

The second test reveal that the observed $p$-value is less than 0.05 that is Prob $>$ chi2 $=$ 0.047 , therefore the null hypothesis can be rejected, hence gross domestic product does granger cause inflation rate. The third test shows that the $p$-value is less than 0.05 that is Prob $>$ chi $2=0.002$, and hence the null hypothesis can be rejected, and we conclude that Money supply does granger cause Inflation rate. And the fourth test of all variables, the $p-$ value is less that the level of significance that is 0.000 , and therefore the null hypothesis can be rejected and hence all variables does granger cause inflation rate.

\subsection{Forecasting}

One of the fundamental applications of time series analysis or developing a time series model is forecasting. The previous discussion confirms that vector auto regressive model of order two is a good model to describe the series. In this section, we examine the forecast for 15 years from 2021 to 2035. Table 9 and Figure 7, presents the forecasted values for inflation rate.

Table 9: Forecasted value of inflation rate from 2020 to 2035

Source: Fieldwork data, 2021

\begin{tabular}{|c|r|}
\hline YEAR & INF_RATE \\
\hline 2020 & 3.7000 \\
\hline 2021 & 1.3627 \\
\hline 2022 & 1.8573 \\
\hline 2023 & 2.3108 \\
\hline 2024 & 2.8400 \\
\hline 2025 & 3.2355 \\
\hline 2026 & 3.4884 \\
\hline 2027 & 3.6207 \\
\hline
\end{tabular}

\begin{tabular}{|c|r|}
\hline YEAR & INF_RATE \\
\hline 2028 & 3.6587 \\
\hline 2029 & 3.6241 \\
\hline 2030 & 3.5310 \\
\hline 2031 & 3.3890 \\
\hline 2032 & 3.2051 \\
\hline 2033 & 2.9856 \\
\hline 2034 & 2.7363 \\
\hline 2035 & 2.4632 \\
\hline
\end{tabular}

The result indicates that there is moderate increase of inflation rate also there is both upward 
and downward trends. There is an upward increase of inflation rate from 2021 up to 2028 reaching $3.7 \%$ and then started to experience a downward decrease from 2029 reaching 2.5 approximately in 2035 as also shown in Figure 7 below.

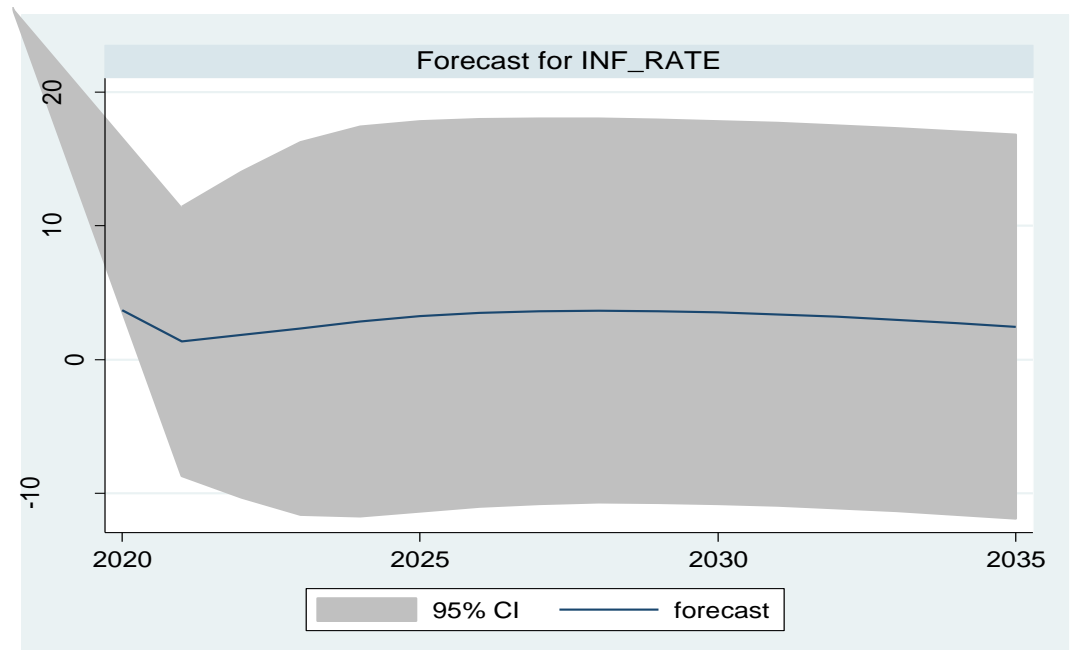

Figure 7: Graph for forecasted value of Inflation rate for 15 years ahead Source: Fieldwork data, 2021

\section{Conclusion}

The objective of the study was to examine the trend of inflation and its key determinants in Tanzania using Vector Autoregressive methodology. Analysis of the data revealed that, there were upward and downward trend of inflation rate while the gross domestic product, money supply and exchange rate trend exhibited upward and downward movement. Also the study revealed that, based on the Vector Autoregressive model results GDP, Money supply and exchange rate are the key factors that explain inflation in Tanzania and money supply and exchange rate have a positive impact on inflation rate while GDP has a negative impact on inflation rate. It is imperative to conclude that Tanzanian inflation is more of monetary factors than real factors. The key policy implication is that inflation in Tanzania is a monetary phenomenon. Thus, to control inflation the government will have to pursue a contractionary monetary and fiscal policies.

\section{References}

Abidemi, O. I., and Malik, S. A. A., 2010. Analysis of Inflation and its determinant in Nigeria. Pakistan Journal of Social Sciences, 7(2), pp. $97 \quad$ - 100. https://doi.org/10.3923/pjssci.2010.97.100.

Alexander, A, A., Andow, A.H., \& Danpome, M.G., 2015. Analysis of the Main Determinants of Inflation in Nigeria. Research Journal of Finance and Accounting, 6(2), pp. 144-155. https://doi.org/10.1002/9781119205524.ch30.

Bashir, F.S., Nawaz, S., Yasin, K., Khursheed, U., and Khan, J., 2011. Determinants of inflation in Pakistan: An econometrics analysis using Johansen Co- integration approach. Australian Journal of Business and Management Research, 1 (5), pp. 71-82. https://doi.org/10.52283/1.ajbmr 
Baciu, I-C., 2015. Stochastic models for forecasting inflation rate. Empirical evidence from Romania. Procedia Economics and Finance, 20, pp. 44-52. https://doi.org/10.1016/s22125671(15)00045-3.

Bank of Tanzania (BOT), 2011. Tanzania mainland's 50 years of Independence: A review of the role and functions of the Bank of Tanzania (1961-2011) [online], available at: https://www.bot.go.tz/Adverts/PressRelease/en/202003130724034239.pdf [accessed 12.03.2021].

Bank of Tanzania (BOT), 2020. Monetary policy statement: The Mid Year Review. Available https://www.bot.go.tz/Publications/Regular/Monetary\%20Policy\%20Statement/en/2020061 515311396.pdf.

Berg, A., Stephen, O., Pattillo, C., Portillo, R., and Unsal, F., 2015. Monetary Policy Issues in Sub-Saharan Africa: forthcoming in Celestin Monga and Justin Yifu Lin eds. The Oxford Handbook of Africa and Economics, Oxford. https://doi.org/10.1093/oxfordhb/9780199687114.001.0001.

Devereaux, M., 1989. A positive theory of inflation and inflation variance. Economic Inquiry, 27(1), pp.105-116. https://doi.org/10.1111/i.1465-7295.1989.tb01166.x.

Farook, A. J., \& Kannan, K. S., 2015. Climate Change Impact on Rice Yield in India - Vector Auto Regression Approach. Sri Lanka Journal of Applied Statistics, 16 (3), pp. 161-178. https://doi.org/10.4038/sljastats.v16i3.7830.

Gujarat, D.N., 2004., Basic Econometrics. McGraw- Hill, New York.

Khalid, A. M., 2005. Economic Growth, Inflation, and Monetary Policy in Pakistan: Preliminary Empirical Estimates. Pakistan Development Review, 44(4), pp. 961-974. https://doi.org/10.30541/v44i4iipp.961-974.

Khan, R, A., and Gill, A. R., 2010. Determinants of Inflation: A Case of Pakistan. Journal of Economics, 1 (1), pp. 45-51. https://doi.org/10.1080/09765239.2010.11884923.

Laryea, S. A., and Sumaila, U. R., 2001. Determinants of Inflation in Tanzania. Chr. Michelsen Institute Development Studies and Human Rights. [online]: Available at: https://www.cmi.no/publications/file/934-determinants-of-inflation-in-tanzania.pdf.

[Accessed 27 May 2021].

McCleary, R., Hay, R. A., Meidinger, E. E., and McDowall, D., 1980. Applied Time Series Analysis for the Social Sciences. Beverly Hills, CA: Sage.

Nguyen, H. M., Cavoli, T., \& Wilson, J. K., 2012. The Determinants of Inflation in Vietnam: ASEAN Economic Bulletin, 29(1), pp. 1-14. https://doi.org/10.1355/ae29-1a.

Shitundu, J, L., and Luvanda, E. G. 2000. The effect of Inflation in economic growth in Tanzania: The African Journal of Finance and Management, 9 (1), pp. 70 -77. https://doi.org/10.4314/ajfm.v9i1.24327.

Xiao, Z., and Phillips, P.C.B., 2002. A CUSUM Test for Cointegration Using Regression Residuals. Journal of Economics, 108 (CFP No. 1046), 43-61. https://doi.org/10.1016/s0304-4076(01)00103-8.

\section{Bio- note}

Cheti Rache/ is a student in the Department of Mathematics and Statistics Studies. Recently, she was attached to National Bureau of Statistics in Tanzania for field work and she developed an interest on time series analysis of economic variables which is also an outcome of this paper we have jointly authored as her supervisor and mentor.

Ilembo Bahati is a lecturer in the Department of Mathematics and Statistics studies and teaches mainly statistics and quantitative techniques. He holds both a Bachelor and Master degrees in Statistics and a PhD in the areas of agricultural economics. His areas of research have been mainly statistical applications to agriculture, development economics and social science in its broad sense. He has published in the areas of agricultural economics in both journal articles and book chapters. 